\title{
Yeşil Mutabakat Çerçevesinde Kentsel Yeşil Alanların Yeşil Altyapı Sistemine Entegrasyonu: Antalya-Konyaaltı Örneği
}

\author{
Serdar SELIM1 1
}

${ }^{1}$ Akdeniz Üniversitesi, Fen Fakültesi, Uzay Bilimleri ve Teknolojileri Bölümü, 07058, Antalya, Türkiye

(Alınış / Received: 13.03.2021, Kabul / Accepted: 13.10.2021, Online Yayınlanma / Published Online: 25.12.2021)

\author{
Anahtar Kelimeler \\ Avrupa yeşil mutabakatı, \\ Yeşil altyapı, \\ Ekolojik ağ, \\ Ekolojik koridor, \\ Uzaktan algilama
}

Özet: Avrupa Yeșil Mutabakatı (A European Green Deal), iklim ve çevreyle ilgili zorluklarla mücadele için kararlı adımlar atılmasını sağlamak üzere 2019 yılında çağrıya çıkan kapsamlı bir büyüme stratejisidir. Bu stratejinin, ekosistem ve biyoçeşitliliği korumak, geliştirmek, sürdürülebilir ve akıllı hareketliliği sağlamak ana başlıkları, yeşil altyapı sistemlerinin temel çıktıları olarak çalışmanın çerçevesini oluşturmaktadır. Yeşil altyapı sistemi, kentsel alanda ekolojik ve sosyal faydaları birleștirmesi yanında eksik olan ekosistem hizmetlerini de sağlama potansiyeline sahiptir. Ancak birçok kent birbirinden bağımsız yeșil alana sahip olmasına rağmen, bağlantıların planlanmamıș olmasından dolayı yeşil altyapı sisteminin faydalarından yararlanamamaktadır. Bu çalışma, kentsel yeşil alanları, yeşil altyapı sistemine entegre ederek bütünleşik bir ekolojik ağ sistemi önermeyi amaçlamaktadır. Bu kapsamda, Antalya ili Konyaaltı bölgesi özelinde uzaktan algilama ve coğrafi bilgi sistemleri kullanılarak uydu görüntüleri yardımıyla kentsel yeşil alanlar belirlenmiștir. Ardından yeşil alanlar, peyzajların yapısal ve ișlevsel devamlılı̆̆ sağlamak üzere, yeșil altyapı sisteminin bağlantı elemanları olan akarsu ve karayolları vasıtasıyla birleștirilerek ekolojik koridorlar oluşturulmuştur. Son olarak, oluşturulan yeşil altyapı sisteminin kent bütününe hizmet edebilmesi açısından, potansiyel ekolojik koridor önerileri sunulmuştur. Bu çalışma, sürekli büyüyen ve genişleyen kentlerde, yeşil alanların ekolojik koridorlar ile birbirine bağlanarak yeşil altyapı sistemlerinin oluşturulmasına ve geliştirilmesine dair örnek oluşturmakta, kentsel planlama stratejilerinde biyolojik çeşitliliğin korunmasına katkı sağlayacak model sunmaktadır.

\section{Integration of Urban Green Lands into Green Infrastructure System in the Framework of European Green Deal: The Case Study of Konyaaltı-Antalya, Turkey}

\section{Keywords \\ European green deal, Green infrastructure, Ecological network, Ecological corridor, Remote sensing}

\begin{abstract}
A European Green Deal is a comprehensive growth strategy called for in 2019 to ensure decisive action to tackle climate and environmental challenges. The main topics of this strategy are to protect ecosystem services and biodiversity, to ensure sustainable and smart mobility. These main headings are the main outputs of green infrastructure systems and these outputs form the framework of the study. Green infrastructure system has the potential to provide missing ecosystem services in many urban areas, as well as combining ecological and social benefits. However, although many cities have independent green spaces, they cannot benefit from the advantages of the green infrastructure system due to the unplanned ecological connections. This study aims to propose a holistic ecological network system by integrating urban green lands into the green infrastructure system. In this context, urban green areas were determined by using remote sensing and geographical information systems with the help of satellite images in Konyaaltı, Antalya/Turkey. Then, in order to ensure the structural and functional continuity of the landscapes, ecological corridors were created by combining green lands with rivers and highways which are the connecting elements of the green infrastructure system. Finally, potential ecological corridor suggestions are presented in order for the established green infrastructure system to serve the whole city. This study is an example of the establishment and development of green infrastructure systems by connecting green lands with ecological corridors in constantly growing and expanding cities and provides a model that will contribute to the protection of biodiversity in urban planning strategies.
\end{abstract}




\section{Giriş}

Küresel çevre sorunları, özellikle 19. yüzyıldan itibaren tüm dünyanın ortak gündemini oluşturmaya başlamıştır [1]. İklim değişikliği, atmosferdeki karbondioksit miktarındaki salınımlar, artan konut ihtiyacına paralel olarak betonlașmanın yeșil alanlar üzerindeki baskıları, biriken atıklar vb. çevre sorunları, ülkeleri küresel ölçekte çözüm arayışlarına yönlendirmiştir [2]. Çevre sorunları ve küresel iklim değişikliğinin uluslararası alanda devletlerin gündemine alınıp ve çözüm arayıșlarının bașlaması, Birleşmiş Milletler tarafından Haziran 1972'de Dünya gündemine taşınmıştır. Konferans sonunda çevre ile uyumlu ekonomik kalkınmaya yönelik bir dizi öneri içeren bildirge açıklanmıştır [3]. Devamında, çevre sorunlarının çok ciddi seviyelere ulaştığı, ekonomik kalkınma için çevre konularının ikinci planda kaldığı, endüstriyel kirliliğin endişe verici seviyelerde olduğu ve yeşil alanlara baskının artarak devam ettiği sonuçları ile 1987 yılında sürdürülebilir kalkınma kavramının da ilk kez ele alındı̆̆ı, "Ortak Geleceğimiz" raporu yayınlanmıştır [4]. 1992 yılında ise çevre ve kalkınma konularının dengeli ve sürdürülebilir bir şekilde yürütülmesi ve biyolojik çeşitlilik sözleşmesi konularında mutabakat sağlanmıştır [5]. Türkiye, 1996 da Biyolojik Çeșitlilik Sözleșmesine ve 2009'da da İklim Değişikliği Çerçeve Sözleşmesine taraf olmuştur. Başta karbondioksit olmak üzere sera gazı salınımlarının dünya genelinde artmaya devam etmesi ve iklim değişikliğinin olumsuz etkilerinin daha da hissedilir olması üzerine 1997'de Kyoto'da Birleşmiş Milletler İklim Değişikliği Çerçeve Sözleşmesi imzalanmıștır [6]. 2015 tarihinde ise, sürdürülebilir şehirler, iklim değişikliği, kuraklıkla mücadele, biyoçeşitliliğin korunması gibi çevre konularını kapsayan "Gündem 2030: BM Sürdürülebilir Kalkınma Hedefleri (SKH)" kabul edilmiştir [7]. Çevre ve sürdürülebilirlik konularında daha keskin ve net adımların atılmasını taahhüt eden "Yeşil Mutabakat (A Europen Green Deal)" çağrısı, 2050 yılına kadar Avrupa kıtasını iklim nötr hale getirmek üzere kapsamlı politikalar tasarlamayı amaçlamaktadır [8, 9]. Yapılan tüm toplantıların temel hedefi iklim ve çevre ile ilgili zorlukların üstesinden gelmek, sürdürülebilir ekolojik kalkınmayı sağlamak, kentleri daha yaşanılabilir hale dönüştürmek ve gelecek nesillere yeşil dokunun aktarımı sağlamak olarak özetlenebilir. Yeşil Mutabakat ile, 2050 yılına kadar net sera gazı emisyonlarının sıfıra indirilmesi ve ekonomik büyümenin kaynak kullanımından ayrılması hedeflenmektedir. Bu bağlamda, "iklim değişikliği ile mücadele", "temiz, erișilebilir ve güvenli enerji”, "temiz, döngüsel ekonomi için sanayi”, "enerji ve kaynak verimliliği sağlanmış binalar", "sürdürülebilir ve akıllı hareketlilik/ulaşım", "tarladan çatala (sofraya) tarım", "ekosistem ve biyoçeşitlilik", "sıfır kirlilik, toksiklerden arınmış çevre", "Avrupa araştırma alt yapılarına destek için bilginin güçlendirilmesi", "vatandaşların sürdürülebilir ve iklim değişikliğinden arındırılmış bir
Avrupa'ya geçiş için hazırlanması (bilgi, beceri)", ve "uluslararası işbirliğini" içeren 11 öncelikli alan altında 20 konu başlığı belirlenmiştir [10]. İlgili konu başlıklarının birçoğu yeşil altyapı sistemlerinin temel çıktılarını oluşturmaktadır. Yeşil altyapı, doğal ve kültürel çevrelerde sürdürülebilir alan kullanımını hedefleyen, ekolojik, sosyal ve çevresel sorunlara stratejik çözümler üreten bir yaklaşımdır. Uygulandığı çevrenin özellikle ekolojik sistemine katkı sağlayan, ekosistem sağlığını iyileștiren, birbiri ile bağlantılı açık yeşil alan sistemidir [11]. Yeşil altyapı sistemi, biyolojik çeşitliliğe katkı sağlarken, birbirinden bağımsız yeșil alanları bağlayarak ekolojik ağ sistemi kurmaktadır. Bu ekolojik ağ sistemi, özellikle kentsel mekanlarda iklimin dengelenmesi, yaban hayatının hareketliliğinin sağlanması, karbondioksit ve oksijen miktarının dengelenmesi, kentsel ısı adası etkilerinin düzenlenmesi gibi birçok faydayı beraberinde getirmektedir [12].

Yeşil altyapı sistemi temelde çekirdek alanlar ve ekolojik koridorlardan oluşmaktadır [12]. Doğal ormanlar, sulak alanlar, geniş alanlara yayılan çayırlıklar, bitki örtüsü yoğun alanlar vb. ekolojik özellikleri yönüyle bütüncül yapı gösteren ve içerisinde yaban hayatını barındıran bölgeler çekirdek alanları oluşturmakta, bu çekirdek alanları doğrusal olarak birbirine bağlayan bitki örtüsü ise ekolojik koridorları oluşturmaktadır. Özellikle kentsel alanlarda, büyük parklar, bitkilendirilmiş ve geniş alanlara yayılmış oyun alanları, rekreasyonel açık yeşil alanlar, kent ormanları vb. bölgeler yeşil altyapı sisteminin çekirdek alanları olarak tanımlanabilir. Yine kentsel alanlarda, yeşil dokuya sahip karayolları, bisiklet yolları, yürüyüş koridorları, akarsular, ana cadde ve sokaklar ekolojik bağlantıların birer elemanı olarak tanımlanabilmektedir. Bu bağlamda birbirine bağlı çekirdek alan sistemleri, hava ve su kalitesini iyileştirme, taşkın kontrolü, yaban hayatına habitat oluşturma, iklimi dengeleme, aktif ve pasif rekreasyonel ihtiyaçları karşılama, yaban hayatının hareketliliğini sağlama vb. gibi birçok faydayı beraberinde getirmektedir [13]. Sosyal, ekonomik ve çevresel sürdürülebilirlik için gerekli olan ekolojik çerçeve, yeşil altyapı sistemleriyle sağlanabilmektedir. $\mathrm{Bu}$ sistem, doğal ve kültürel alanlarda ekolojik özellikleri bakımından değerli görülen her bir parçayı peyzaj sistemi içerisine dahil ederek bir bütün olarak kapsayan, kentsel yaşamı destekleyen ve geliștiren bütüncül bir sistemdir. Bunun yanında planlama süreçlerinde yapısal çalışmaların tamamlayıcısı olan ve ekolojik çözümler üreten kapsamlı bir sistemin en önemli bileșenidir.

Tüm bu özellikleri, yeşil altyapı sistemlerinin kurulmasını ve mekânsal planlamalarda dikkate alınması gerekliliğini doğurmaktadır. Ancak günümüzde, özellikle kentlerdeki yeşil alanlar özelinde bütüncül bir sistemden bahsetmek mümkün değildir. Kişi başına düşen yeşil alan miktarının yeterli olduğu kentlerde bile bu yeşil doku birbirinden 
bağımsız ve kopuk olarak görülmektedir [14]. İmar adaları arasında kalan tanımsız boşluklar park olarak nitelendirilmekte ancak bir kent sistemi içerisinde bütünün parçaları olarak görülmemektedir [15]. Birbirinden bağımsız olarak oluşturulan veya doğal olarak var olan ancak kentleşme baskısı ile küçülen ve diğer habitatlarla bağlantısı kopan alanlar için bütüncül ve kapsayıcl bir ekolojik sistemin oluşturulması gerekmektedir. $\mathrm{Bu}$ gereklilik, Yeşil Mutabakat kapsamında 2050 yılı hedeflerine ulaşmada yeşil altyapı sistemlerinin kurulması ön plana çıkarmaktadır. Ayrıca yeşil altyapı, Avrupa Komisyonu tarafından 2030'a kadar Avrupa Birliği Biyolojik Çeşitlilik Stratejisinde ekosistemlerin korunması için önemli bir araç olarak tanıtılmaktadır [16].

Bu çalışma, Yeşil Mutabakat kapsamında belirlenen 11 öncelikli alandan, İklim Değişikliği ile Mücadele, Sürdürülebilir ve akıllı hareketlilik/ulaşım, Ekosistem ve Biyoçeşitlilik, Sıfır kirlilik, Toksiklerden arınmış çevre ana başlıklarına doğrudan katkı sağlamak üzere kentsel alanda var olan peyzaj bileşenlerini birbiri ile bağlantılı bütüncül bir sisteme dönüștürmeyi hedefleyen, bu kapsamda yeşil altyapı sistemlerini kuran ve bu sistemin sürdürülebilirliği için öneriler geliştiren uygulanabilir örneklerden birini sunmaktadır.

Bu çalışma kapsamında öncelikle sosyal, kültürel ve çevresel özellikleri nedeniyle değerli görülen bir örneklem alanı seçilmiş, bu örneklem alanı uzaktan algılama ve coğrafi bilgi sistemleri ile sayısallaştırılarak yeșil altyapı bileşenleri kapsamında sınıflandırılmış, sistemin bileşenleri belirlenerek bağlantıları oluşturulmuş, bağımsız bileşenlerin ise bu ağ sistemine dahil edilmesi için gerekli bağlantı önerileri sunulmuştur. Kent ölçeğinde hazırlanan bu çalışmanın, Yeşil Mutabakat çerçevesinde birçok kent ve bölge için uygulanabilir olması sebebiyle yaygın etkiye sahip olduğu öngörülmektedir.

\section{Materyal ve Metot}

Birbiri ile bağlantılı açık yeşil alan sisteminin kentlere entegrasyonu üzerine odaklanan bu çalışma, Türkiye'nin en önemli turizm destinasyonlarının başında gelen Antalya ili, Konyaaltı bölgesi ve yakın çevresinde yürütülmüştür. Çalışmanın temel materyalini kapsayan Konyaaltı ilçesindeki açık yeşil alanlar, uzaktan algılama yöntemleriyle kentsel tasarım perspektifinde yeşil altyapı sistemini oluşturacak şekilde kurgulanmıştır.

\subsection{Materyal}

Çalışma, Antalya ili Konyaaltı bölgesi ve yakın çevresini kapsayan, turizm potansiyeli bakımından oldukça yüksek, kentleșmenin ve hareketliliğin yoğun olduğu bir alanda yürütülmüştür. Çalışma alanını içerisine alan köşe koordinatları; 3655'42.27"K ve $30^{\circ} 43^{\prime} 45.47^{\prime \prime} \mathrm{D}, \quad 36^{\circ} 55^{\prime} 21.97 " \mathrm{~K}$ ve $30^{\circ} 35^{\prime} 47.92^{\prime \prime D}$, $36^{\circ} 51^{\prime} 29.45^{\prime \prime} \mathrm{K}$ ve $30^{\circ} 36^{\prime} 12.85^{\prime \prime} \mathrm{D}, 36^{\circ} 51^{\prime} 51.20^{\prime \prime} \mathrm{K}$ ve $30^{\circ} 43^{\prime} 57.06^{\prime \prime D}$ şeklindedir (Şekil 1). İlçenin temel ekonomik ve ticari faaliyeti turizm sektörü ile bu sektöre bağlı olarak gelişen hizmet sektörüne dayanmakta ve bölgede çok sayıda otel bulunmaktadır.

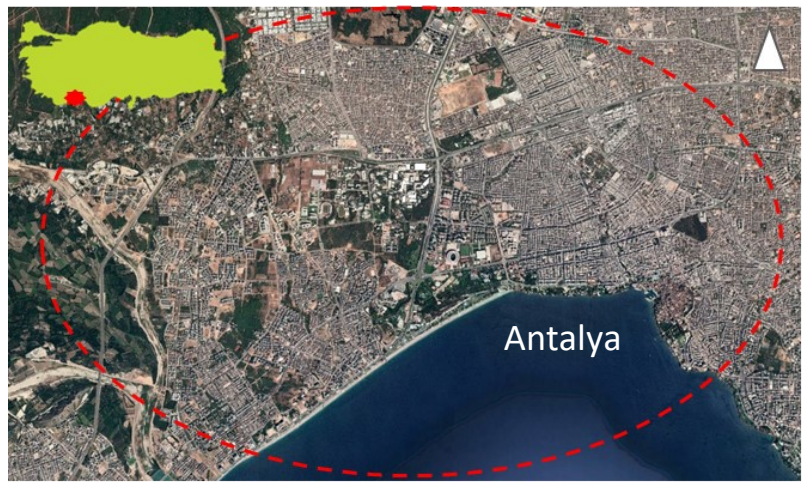

Şekil 1. Çalışma alanı konumu

Antalya ili, Türkiye'nin en kalabalık 5. ili olarak yaklaşık 2,5 milyon nüfusa ve 20 bin $\mathrm{km}^{2}$ lik bir alana sahiptir [17]. Çalışma alanı ise ilin Konyaaltı ilçesiyle birlikte, Kepez, Muratpaşa ve Döşemealtı ilçelerinin bir bölümünü kapsamaktadır. Sadece Konyaaltı ilçesinde, Konyaaltı İlçe Nüfus Müdürlüğü verilerine göre ortalama 200 bin kişi yaşamaktadır.

Çalışma alanının ve sınırlarının seçiminde, kentsel gelişmenin yoğun olması, yapılaşmanın devam etmesi, doğal ve kültürel alanları içerisinde barındırması, turist hareketliliğinin ve insan sirkülasyonunun fazla olması etkili olmuştur. Ayrıca 1 milyon 438 bin 847 metrekare toplam yeşil alan ile Konyaaltı İlçesi'nde kiși başına 11,62 metrekare yeșil alan düștüğü ifade edilmektedir [18]. Çalıșmada yardımcı materyal olarak, Haziran 2020 tarihli 30 m çözünürlüklü Landsat 8 uydu görüntüleri ve görüntüleri işlemek üzere, QGIS 3.6 ve ArcGIS 10.4 yazılımları kullanılmıştır (Tablo 1).

Tablo 1. Kullanılan uydu görüntüsü özellikleri

\begin{tabular}{clcc}
\hline \multirow{2}{*}{$\begin{array}{c}\text { Landsat 8 } \\
\text { Operational } \\
\text { land } \\
\text { Imager } \\
\text { (OLI) }\end{array}$} & \multicolumn{1}{c}{ Bantlar } & $\begin{array}{c}\text { Dalga boyu } \\
(\mu \mathrm{m})\end{array}$ & $\begin{array}{c}\text { Çözünürlük } \\
(\mathrm{m})\end{array}$ \\
\cline { 2 - 4 } & Bant 2- Mavi & $0.45-0.51$ & 30 \\
\cline { 2 - 4 } & Bant 3 - Yeșil & $0.53-0.59$ & 30 \\
\cline { 2 - 4 } & Bant 4 - Kırmızı & $0.64-0.67$ & 30 \\
\hline kant 5 - Yakın & $0.85-0.88$ & 30 \\
\hline
\end{tabular}

\subsection{Yöntem}

Çalışma yöntemi dört temel aşamadan oluşmaktadır (Şekil 2). 1- Veri toplama; bu aşamada çalıșma alanına ait uydu görüntüleri açı erişimde olan https://earthexplorer.usgs.gov/ internet sitesi üzerinden online olarak indirilmiştir. Ayrıca yeşil altyapı (YA) sistemi elemanları ve güncel yeşil altyapı stratejilerine yönelik literatür araştırması yapılmış, yazılı ve görsel dokümanlar temin edilmiştir. 2- 
Sayısallaştırma; bu aşamada ise uydu görüntüsü için radyometrik ve geometrik düzeltme ön işlemleri gerçekleştirilmiş, çalışma alanı sınırları belirlenmiş ve yeşil doku analizine hazırlık olması için bölgenin NDVI (normalize edilmiş bitki indexi) görüntüsü oluşturulmuştur. Ardından uydu görüntüsüne kontrollü sınıflandırma (maximum likelihood classification) işlemi uygulanmış, yeşil doku, yerleşim ve su yüzeyi olmak üzere 3 sınıfa ayrılmıştır. Elde edilen görüntüler üzerinden, araştırma alanındaki karayolları sayısallaştırılmış ve altlık harita üretilmiştir.

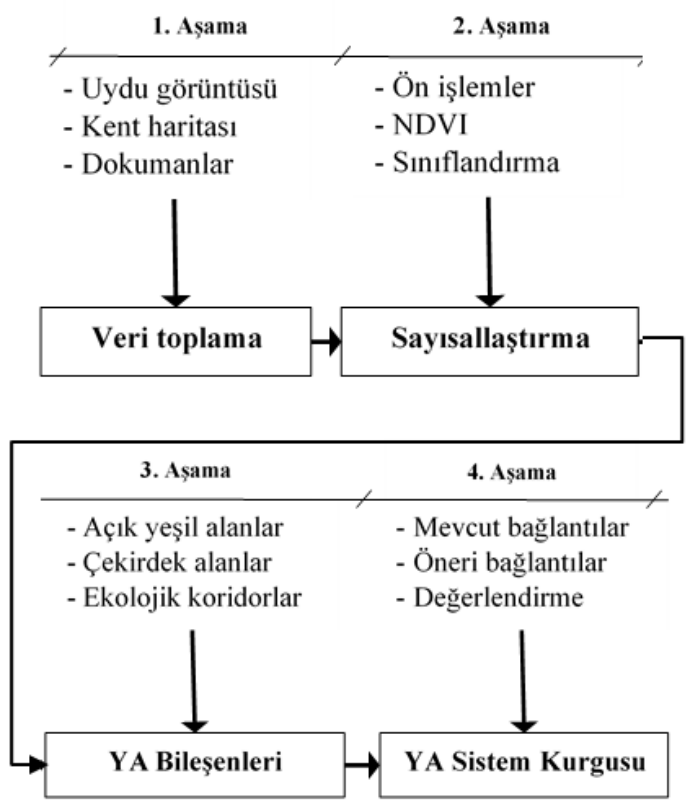

Şekil 2. Yöntem akış şeması

3- Yeşil altyapı bileşenlerinin tanımlanması; çekirdek alanlar ve ekolojik koridorlardan oluşan yeşil altyapı bileşenleri, çalışma alanının ekolojik, fiziksel ve coğrafi özellikleri dikkate alınarak literatür verileri doğrultusunda belirlenmiş ve sayısallaştırılarak harita üzerine aktarılmıştır. Bu aşamada, doğal ve kültürel ormanlar, kent parkları, bitkilendirilmiş meydanlar, mezarlıklar, kent içi ağaçlıklı alanlar çekirdek alan olarak [19-21], akarsu kolları, karayolları, bisiklet yolları ve doğrusal özellik gösteren yürüme yolları ekolojik koridorlar olarak belirlenmiştir [22-24], 4Son aşamada ise çekirdek alanlar ile ekolojik koridor olarak belirlenen doğrusal özellik gösteren yolların kent ölçeğinde bağlantıları sağlanmıştır. Bağlantıların oluşturulmasında, her bir çekirdek alana mümkün olan en kısa güzergâh ile ulaşma ve ekosistem özellikleri yönü ile geniş çekirdek alanlardan daha fazla bağlantının yapılması esas alınmıştır [13, 25-26].

\section{Bulgular}

Çalışma alanı 83,46 km² lik bir alanı kapsamakta, Konyaaltı sahil şeridi, Antalya kent merkezi ve kuzeyde Döşemealtı ilçesi sınırlarına kadar önemli bir açık yeşil alan varlığı barındırmaktadır. Uydu görüntülerinden kontrollü sınıflandırma yöntemi ile elde edilen açık yeşil alanlar, bölgenin kuzeybatısında daha çok doğal ormanların bulunduğu yerlerde yoğunlaşmaktadır. Kent içinde ise üniversite kampüsü ile yapımı yeni tamamlanan Konyaaltı sahil parkı kısımlarında ve kıyı şeridi boyunca ince ve uzun bir hat oluşturmaktadır. Çalışma alanı bütününde mevcut yeşil alanlar 24 farklı peyzaj yamasında 2.527 ha lık bir alana yayılmıștır (Şekil 3). Bu yeșil alanlar, yerleşim baskısı altında parçalı ve bölünmüş bir yapı gösterse de alanın batısında genel itibariyle bütünlüklerini koruyabilmiştir. Kentsel yerleşimin daha yoğun olduğu doğu kısımlarında ise kent bütününe hizmet edebilecek işlevsel yeșil alanların azlığı dikkat çekmektedir.

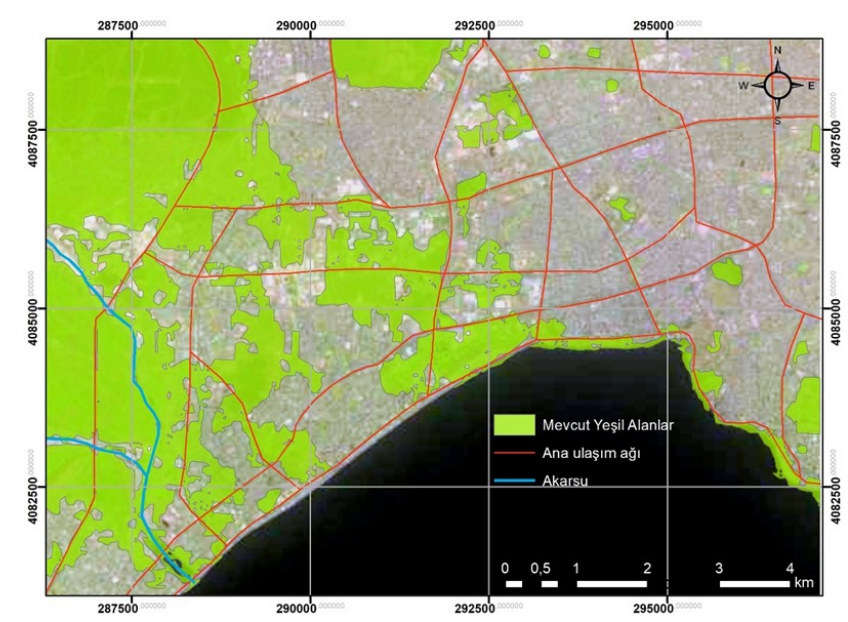

Şekil 3. Mevcut açık yeşil alanlar ve ana ulaşım sistemi

Alanın kuzeyi ve batısı, topoğrafik yapı itibariyle deniz seviyesine göre yüksek olduğundan yerleșimler burada daha seyrek görülmekte, buna bağlı olarak doğal habitatlar buralarda daha yoğun bulunmaktadır. Bölgenin orta kısımlarındaki açık yeşil alanların kısmen bağlantıları olmasına rağmen, parçalı ve bölünmüş yapı göstermeleri, habitat içerisinde delinmelerin olması ve kompakt bir yapıdan ziyade dar bir alanda uzun kenarlara sahip olması, bu peyzaj yamalarının baskı altında olduğunu ortaya çıkarmaktadır. Bu yeşil alanlar arasında kente hizmet eden ana ulaşım sistemi, genel itibariyle doğu-batı istikametinde olup, kuzey-güney yönünde ara bağlantılar ile kent bütününü sirküle etmektedir. Alanın batısında iki yan kol ile kuzeyden gelen akarsu, birleşerek tek bir kol halinde Akdeniz'e dökülmektedir. Akarsu çevresindeki yeşil alanların miktarı, burada önemli bir yaban hayatı habitatı olduğunu göstermektedir.

Yeşil altyapı sisteminin kurulması ve çalışma alanı özelinde kentin mevcut yapısına entegre edilmesini sağlamak üzere kentteki yeşil alanların, ekolojik işlevleri ve büyüklükleri dikkate alınarak 2 ha [16] ve üzerinde olanları çekirdek alan olarak belirlenmiştir. Belirlenen bu çekirdek alanları çalışma alanı özelinde doğal ormanlar, kent meydanları, üniversite kampüsü, mezarlıklar, sahil parkları, kent parkları ve zeytinlikler oluşturmaktadır (Şekil 4). 


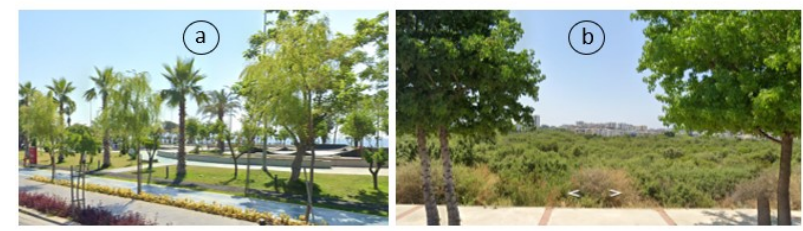

Şekil 4. a) Sahil parkı çekirdek alanı, b) Üniversite kampüsü çekirdek alanı

Mevcut çekirdek alanlar, gerek parçalı bir yapı göstermesi itibariyle kendi içerisinde gerekse de diğer peyzaj yamalarıyla kısmi ekolojik bağlantılara sahiptir. Çalışmadaki ekolojik koridorlar, ekolojik olarak yüksek kaliteli korunan alanlar dahil olmak üzere en güvenli ve ekolojik açıdan önemli habitat yamalarının (çekirdek alanların) bağlantısı olarak belirlenmiştir. Bu mevcut ekolojik koridorları ise yine çalışma alanı özelinde sahil şeridi, ağaçlandırılmış yollar, akarsu kolları ve orman parçaları oluşturmaktadır (Şekil 5).
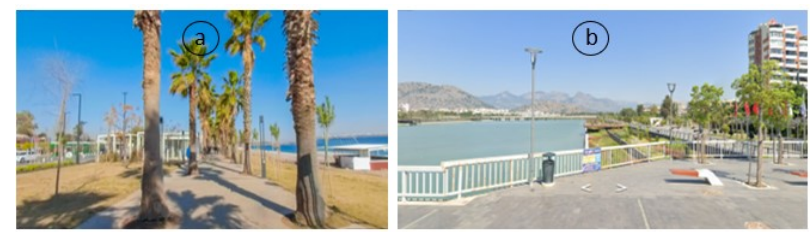

Şekil 5. a) Sahil şeridi ekolojik koridoru, b) Akarsu ekolojik koridoru

Çalışma alanı bütününde, ekolojik özellikleri ve işlevleri yönüyle değerli görülen ve yeşil altyapı sisteminin birer bileșeni olarak kabul edilen 18 çekirdek alan ve bu çekirdek alanların bazılarını birbirine bağlayan 15 ekolojik koridor tespit edilmiştir (Şekil 6). Çekirdek alanların en küçüğü 2 ha ve en büyüğü 1.844 ha olmak üzere farklı büyüklüklerde ve şekillerdedir. Ekolojik koridorlar ise genişlikleri değişmekle birlikte $1 \mathrm{~km}$ ile $5,6 \mathrm{~km}$ arasında uzunluklara sahiptir.

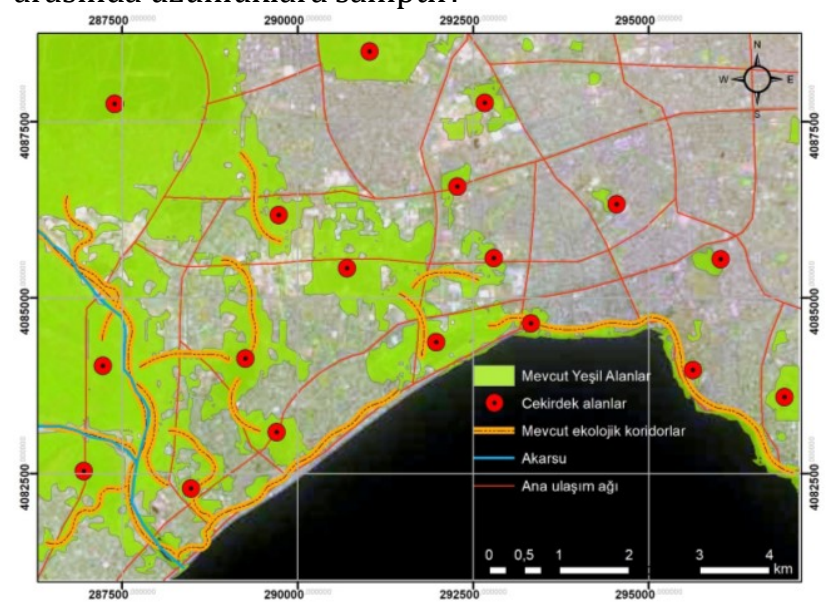

Şekil 6. Mevcut çekirdek alanlar ve ekolojik koridorlar

Şekil 6'da da görüldüğü üzere, kentsel çekirdek alanlar kentin batısında bulunan doğal popülasyonlara doğru kısmen bütüncül bir yapı göstermesine karşın kentsel yerleşimin yoğun olduğu doğu kısımlara doğru parçalı bir yapıya dönüşmektedir. Ekolojik özellikleri ve işlevleri yönüyle çekirdek alan ve ekolojik koridor olarak belirlenen yeşil alanlar, tamamen bütüncül ve kompakt bir yapı göstermemekte, delinme ve parçalanma tehditleri ile karşı karşıya kalmaktadır.

Yeşil Mutabakat kapsamında ele alınan sürdürülebilir kentsel gelişim için yeşil altyapı sistemlerinin, kentin mevcut dokusunu destekleyici, ekosistem servislerini ve biyoçeşitliliği teşvik edici, sosyal, kültürel ve ekolojik olarak kent bütününe katkı sağlayıcı bir şekilde planlanmasını sağlayabilmek üzere, çalışma alanında bütüncül bir ekolojik ağ sistemi geliştirilmiștir (Şekil 7).

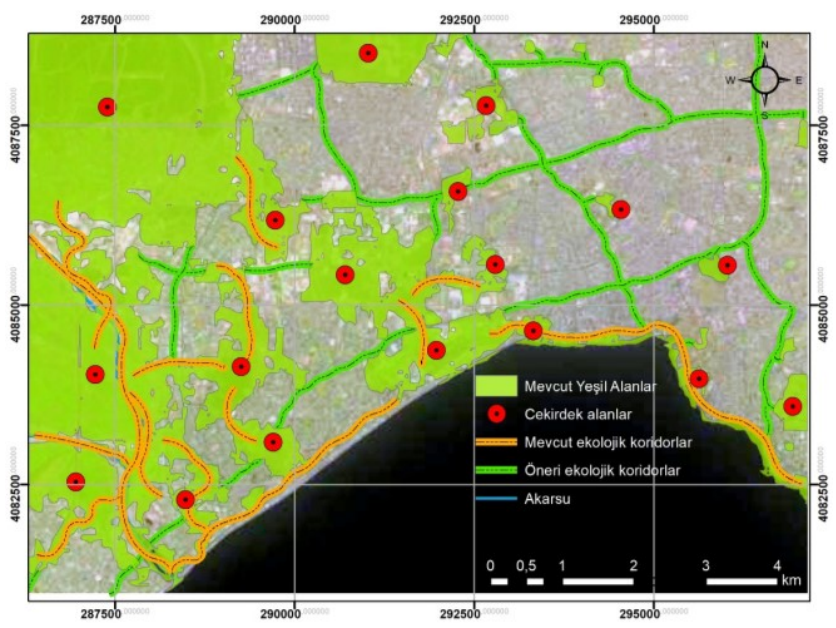

Şekil 7. Mevcut peyzaj yapısının yeșil altyapı sistemine entegrasyonu

Kentsel biyoçeşitliliği desteklemek, yaban hayatı popülasyonlarının hareket alanları geliştirmek, ekosistem servisleri teşvik etmek ve kentin sosyokültürel yapısına katkı sağlamak önceliği ile kurgulanan yeşil altyapı sistemi, çekirdek alan olan tanımlanan bölgeleri birbirine bağlamak üzere mevcuda ek olarak 32 ekolojik koridor önerisi sunmaktadır. Öneri ekolojik koridorlar, kent bütününde çekirdek alanları ve daha küçük ölçekli açık yeşil alanları bir ağ sistemi ile birbirine bağlamakta ve kent geneline yayılmaktadır. $0,2 \mathrm{~km}$ ile $6,2 \mathrm{~km}$ arasında çeşitli uzunluklara sahip olan öneri ekolojik koridorlar, yerel yaban hayatı popülasyonlarına habitat alanı sağlama yanında, kent içindeki sosyal yaşamın da hareketliliğini geliştirmek üzere bütüncül bir yapı oluşturmaktadır. Doğu-batı yönünde önerilen 2 ana ekolojik koridor ağı ile kentin, sosyal ve kültürel olarak önemli görülen merkezlerine de yaya hareketini teşvik etmektedir. Yine kuzeygüney yönündeki öneri ekolojik koridor bağlantıları ile yalıtılmış habitatlara yayılıș ve üreme alanı sağlamaktadır. Önerilen yeşil altyapı sistemi, çalışma alanının yakın çevre bağlantılarını da geliştirmek üzere dinamik bir şekilde kurgulanmıştır. Kentsel tasarım ölçeğinde de, önerilen ekolojik koridorlar için tasarım geliştirilmiş, bu tasarımda sistemin kente ve kentsel ekosisteme katkıları belirtilmiştir (Şekil 8). 


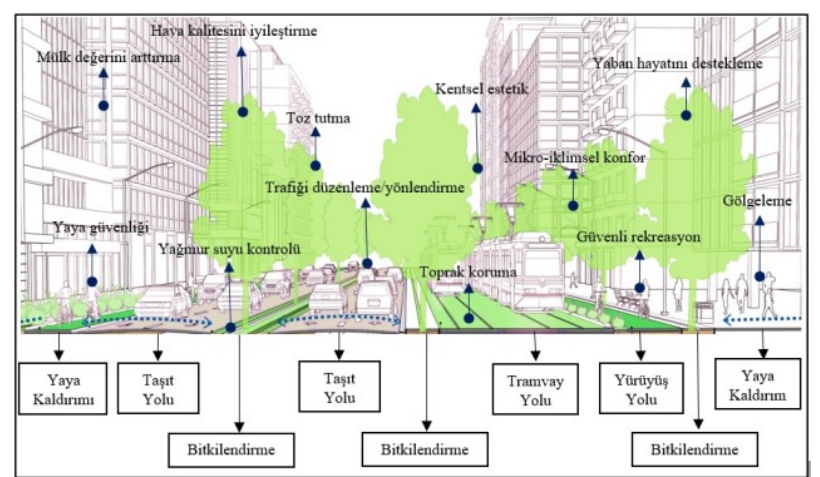

Şekil 8. Önerilen ekolojik koridorlara yönelik geliștirilen kentsel tasarım ([27]'den geliștirilerek)

Ekolojik koridor olarak planlanan kentsel ulaşım ağının ekosistem servislerini geliştirme ve kentsel estetiği teşvik etme gibi birçok işlevi bulunmaktadır. Yaban hayatı hareket sahasının geliştirilmesi yanında yaya trafiğini de düzenleyerek mikro-iklimsel konfor oluşturmakta ve kentleri daha yaşanılabilir hale dönüştürmektedir. Oluşturulan yeşil yüzeyler sayesinde yağmur suyu kontrolünü sağlamakta ve toprak canlılı̆̆ını desteklemektedir. Bunun yanında, kentsel ekolojik koridorlar uygulandı̆̆ı bölgelerde mülk değerini arttırmakta [27], yürüyüş ve bisiklet aktiviteleri için güvenli ortamlar oluşturmaktadır.

\section{Tartışma ve Sonuç}

2050 yılına kadar sera gazı salınımını sıfırlamayı, ekosistem servislerini ve biyolojik çeşitliliği desteklemeyi, sürdürülebilir ve akıllı hareketliliği sağlamayı hedefleyen Avrupa Yeşil Mutabakatı, kent ölçeğinde yeşil altyapı sistemlerini kurmayı öneren ve kurgulayan bu çalışmanın temel çerçevesini oluşturmuştur. Yeşil altyapı sistemleri, ülke-bölge ve kent ölçeklerinde peyzaj sistemini bütünleştirici mantığı ile hareket eden ekolojik planlama yöntemlerinin bir tamamlayıcısıdır [13]. Sürdürülebilirlik temelinde, doğal ve kültürel yaşam ortamlarını koruyup geliştiren sistematik bir yaklaşım ürünüdür. Dolayısıyla Yeşil Mutabakatın sağlanması için gerekli olan uygulamaların temel adımlarından bir tanesidir. Uluslararası düzeydeki birçok yeşil altyapı planı, özellikle habitat bağlantılarının sağlanması ve ekosistem servislerinin geliştirilmesi amacına yönelmektedir (Şekil 9).

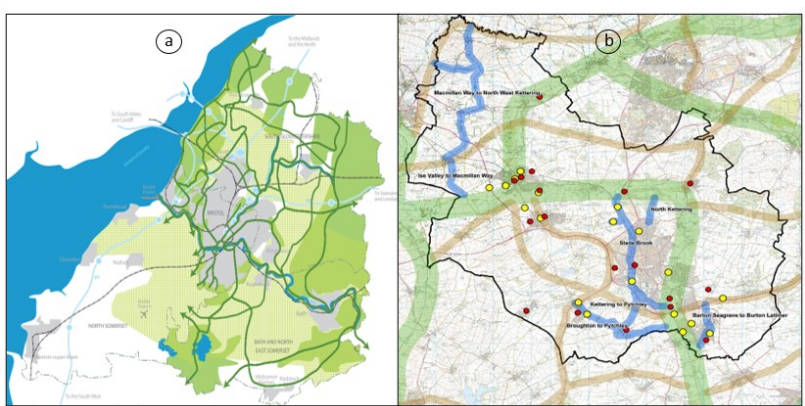

Şekil 9. (a)Bölge ölçeğinde Batı İngiltere YA stratejisi [28] ve (b)Kent ölçeğinde Kettering Borough YA planı [29]
Batı İngiltere'nin habitat bağlantılarını sağlamak üzere planladığı yeşil altyapı sisteminde (Şekil 9a), ana ulaşım ağı ve akarsu koridorları ekolojik koridor olarak bölgede bir ağ sistemi oluşturmaktadır [28]. Bölge ölçeğinde yapılan planlama, yerel ölçeklerde uygulama adımlarına kadar geniş ve kapsamlı bir süreci meydana getirmiştir. Yeşil alanların çekirdek alan olarak tanımlanması ve doğrusal özellik gösteren güzergahların ekolojik koridor olarak belirlenmesi, bu çalışmanın mantığı ile örtüşmektedir. Bu çalışmayı batı İngiltere yeşil altyapı planından ayıran en önemli özellik ise, kent ölçeğinde ekolojik koridor tasarımının geliştirilmesi ve bu kapsamda, kent içi sosyal yaşamın hareketliliğini sağlayacak öneri sunmasıdır. Şekil 9 (b)'de ise kent ölçeğinde Kettering Borough'un yeşil altyapı stratejisi oluşturulmuş, özellikle kentin, kent dışı ile bağlantılarının sağlanması hedeflenmiştir [29]. Kent içi açı yeşil alan sisteminin yeşil altyapı planına bu ölçekte dahil edilmediği çalışma, uygulama için daha küçük ölçeklerde yeni planlamaları yapmak mecburiyetini doğurmaktadır [30]. Konyaaltı ve yakın çevresinin yeşil altyapı sistemini stratejik olarak planlayan bu çalışma, çok fonksiyonlu ve çok ölçekli olarak düşünülmüş, uygulama için öneri geliştirerek mekânsal planlamaları yönlendirici etki ortaya koymayı öngörmüştür. Ekosistem servislerini ve biyolojik çeşitliliği destekleyici [31] etkisinin yanısıra, kentli için daha yaşanılabilir bir çevre oluşturmak, kent estetiğine pozitif değer katmak [20], yaya hareketliliğini teşvik etmek [32] işlevlerini başarmayı hedeflemiştir. Dolayısıyla Yeşil Mutabakatın 2030 ve 2050 hedeflerine ulaşabilmesinde yerel ölçekte çözüm önerisi geliştirmiştir.

Yeşil Mutabakatın hedeflerine ulaşmada, mevcut açık yeşil alan sistemini, bütüncül bir yeşil altyapı planı kurarak bu plana entegre eden çalıșma ile, kent iklimini düzenlemek [33], ekosistem sağlığını geliștirmek [20], sürdürülebilir hareketliliği sağlamak [32], biyoçeşitliliği desteklemek [34] ve daha yaşanılabilir çevreler oluşturmak [35] hedeflenmiş, bu hedef doğrultusunda kent ölçeğinde kapsamlı bir öneri ortaya konulmuştur.

\section{Etik Beyanı}

Bu çalışmada, "Yükseköğretim Kurumları Bilimsel Araştırma ve Yayın Etiği Yönergesi" kapsamında uyulması gerekli tüm kurallara uyulduğunu, bahsi geçen yönergenin "Bilimsel Araştırma ve Yayın Etiğine Aykırı Eylemler" başlığı altında belirtilen eylemlerden hiçbirinin gerçekleştirilmediğini taahhüt ederiz.

\section{Kaynakça}

[1] Coleman, S., Hurley, S., Koliba, C., Zia, A. 2017. Crowdsourced Delphis: Designing solutions to complex environmental problems with broad stakeholder participation. Global Environmental Change, 45, 111-123. 
[2] Minx, J. C., Callaghan, M., Lamb, W. F., Garard, J., Edenhofer, O. 2017. Learning about climate change solutions in the IPCC and beyond. Environmental Science \& Policy, 77, 252-259.

[3] Seyfang, G. 2003. Environmental megaconferences-from Stockholm to Johannesburg and beyond. Global Environmental Change, 13(3), 223-228.

[4] Redclift, M. 2005. Sustainable development (1987-2005): an oxymoron comes of age. Sustainable development, 13(4), 212-227.

[5] Rogalla von Bieberstein, K., Sattout, E., Christensen, M., Pisupati, B., Burgess, N. D., Harrison, J., Geldmann, J. 2019. Improving collaboration in the implementation of global biodiversity conventions. Conservation Biology, 33(4), 821-831.

[6] Bolin, B. 1998. The Kyoto negotiations on climate change: a science perspective. Science, 279(5349), 330-331.

[7] Biermann, F., Kanie, N., Kim, R. E. 2017. Global governance by goal-setting: the novel approach of the UN Sustainable Development Goals. Current Opinion in Environmental Sustainability, 26, 26-31.

[8] Siddi, M. 2020. The European Green Deal: assessing its current state and future implementation. Climate Policy, 16(5), 543-547.

[9] Sikora, A. 2021. European Green Deal-legal and financial challenges of the climate change. In ERA Forum 21(4), 681-697.

[10] EU, 2021, An Official Website of the European Union, The EU aims to be climate-neutral by 2050,https://ec.europa.eu/clima/policies/strat egies/2050_en (Erişim tarihi: 01.03.2021)

[11] Selim, S., Kaplan, A. 2016. Engaging Green Infrastructure Scheme into Watershed- and Urban-based Planning and Design Realms, Proceedings of the Fábos Conference on Landscape and Greenway Planning, 5(2), 15.

[12] Benedict, M.A., McMahon, E.T. 2006. Green Infrastructure: Linking Landscapes and Communities, Washington, D.C., Island Press, 299s.

[13] Mell, I.C. 2010. Green Infrastructure: Concepts, Perceptions and Its Use in Spatial Planning, PhD Thesis, School of Architecture Planning and Landscape, Newcastle University, UK, 291s.

[14] Wei, J., Qian, J., Tao, Y., Hu, F., Ou, W. 2018. Evaluating spatial priority of urban green infrastructure for urban sustainability in areas of rapid urbanization: A case study of Pukou in China. Sustainability, 10(2), 327.
[15] Lee, Y. C., Kim, K. H. 2015. Attitudes of citizens towards urban parks and green spaces for urban sustainability: The case of Gyeongsan City, Republic of Korea. Sustainability, 7(7), 82408254.

[16] Furberg, D., Ban, Y., Mörtberg, U. 2020. Monitoring urban green infrastructure changes and impact on habitat connectivity using highresolution satellite data. Remote Sensing, 12(18), 3072.

[17] Antalya Valiliği, 2021. Antalya Valiliği Resmi Internet Sitesi, http://www.antalya.gov.tr/antalyanin-2020yili-nufusu-belli-oldu (Erişim tarihi: 01.03.2021)

[18] Konyaaltı Belediyesi, 2021. Konyaaltı Belediyesi Resmi İnternet Sitesi, https://konyaalti.bel.tr/haberler/17678antalya-nin-yesil-dokusu-konyaalti-nda (Erişim tarihi: 26.02.2021)

[19] Chen, W. Y. 2015. The role of urban green infrastructure in offsetting carbon emissions in 35 major Chinese cities: A nationwide estimate. Cities, 44, 112-120.

[20] Tzoulas, K., Korpela, K., Venn, S., Yli-Pelkonen, V., Kaźmierczak, A., Niemela, J., James, P. 2007. Promoting ecosystem and human health in urban areas using Green Infrastructure: A literature review. Landscape and urban planning, 81(3), 167-178.

[21] Sanesi, G., Colangelo, G., Lafortezza, R., Calvo, E., Davies, C. 2017. Urban green infrastructure and urban forests: A case study of the Metropolitan Area of Milan. Landscape Research, 42(2), 164175.

[22] Vergnes, A., Kerbiriou, C., Clergeau, P. 2013. Ecological corridors also operate in an urban matrix: a test case with garden shrews. Urban Ecosystems, 16(3), 511-525.

[23] Peng, J., Zhao, H., Liu, Y. 2017. Urban ecological corridors construction: A review. Acta Ecologica Sinica, 37(1), 23-30.

[24] Li, F., Liu, X., Zhang, X., Zhao, D., Liu, H., Zhou, C., Wang, R. 2017. Urban ecological infrastructure: an integrated network for ecosystem services and sustainable urban systems. Journal of Cleaner Production, 163, 12-18.

[25] Weber, T., Sloan, A., Wolf, J. 2006. Maryland's Green Infrastructure Assessment: Development of a comprehensive approach to land conservation. Landscape and urban planning, 77(1-2), 94-110.

[26] Jia, Y. P., Lu, K. F., Zheng, T., Li, X. B., Liu, X., Peng, Z. R., He, H. D. 2021. Effects of roadside green 
infrastructure on particle exposure: A focus on cyclists and pedestrians on pathways between urban roads and vegetative barriers. Atmospheric Pollution Research, 12(3), 1-12.

[27] GDCI, 2021. Global Designing Cities Initiative, https://globaldesigningcities.org/publication /global-street-design-guide/utilities-andinfrastructure/green-infrastructurestormwater-management/ (Erişim tarihi: 01.03.2021)

[28] Westofengland, 2011. West of England Strategic Green Infrastructure Framework, West of England Partnership, Natural England, Environment Agency, and Forestry Commission, http://www.westofengland.org/media/216918 /gi\%20framework\%20020611.pdf (Erişim tarihi: 03.03.2021).

[29] River Nene National Park, 2018. A Green Infrastructure Delivery Plan for the Kettering Borough, Kettering Borough Council Information, Environment Agency, 126p.

[30] Zaręba, A. 2014. Multifunctional and multiscale aspects of green infrastructure in contemporary research. Problems of Sustainable Development, 9(121), 149-156.
[31] Coutts, C., Hahn, M. 2015. Green infrastructure, ecosystem services, and human health. International journal of environmental research and public health, 12(8), 9768-9798.

[32] Zhang, Z., Meerow, S., Newell, J. P., Lindquist, M. 2019. Enhancing landscape connectivity through multifunctional green infrastructure corridor modeling and design. Urban Forestry \& Urban Greening, 38, 305-317.

[33] Foster, J., Lowe, A., Winkelman, S. 2011. The value of green infrastructure for urban climate adaptation. Center for Clean Air Policy, 750(1), 152.

[34] Özcan, K. Y. 2019. Yeşil Yeni Düzen ve Yeşil Büyüme Bağlamında Kayseri, Sakarya, Hatay ve Samsun Örnekleri. Süleyman Demirel Üniversitesi Fen Bilimleri Enstitüsü Dergisi, 23(3), 1013-1031.

[35] Olgun, R., Yılmaz, T. 2019. İmar Planlarının Peyzaj Ekolojisi Yaklaşımı ile Değerlendirilmesi: Niğde Kenti Örneği. Süleyman Demirel Üniversitesi Fen Bilimleri Enstitüsü Dergisi, 23(3), 770-779. 